\title{
1 On the extraordinary winter flood episode over the North Atlantic Basin in 1936
}

2 Juan Antonio Ballesteros Cánovas (* 1,2); Markus Stoffel (1,2,3); Gerardo Benito (4); Mario Rohrer (1,5);

3 David Barriopedro (6); Ricardo García-Herrera (6,7); Martin Beniston (1); Stefan Brönnimann (8)

4 (1) Climatic Change Impacts and Risks in the Anthropocene (C-CIA), Institute for Environmental Sciences,

5 University of Geneva, $\mathrm{CH}-1205$ Geneva, Switzerland

6 (2) Dendrolab.ch, Department of Earth Sciences, University of Geneva, CH-1205 Geneva, Switzerland

7 (3) Department F.A. Forel for Aquatic and Environmental Sciences, University of Geneva, $\mathrm{CH}-1205$

8 Geneva, Switzerland

9 (4) Museo Nacional de Ciencias Naturales, CSIC, 28006 Madrid, Spain

10 (5) Meteodat $\mathrm{GmbH}$, Zürich

11 (6) Instituto de Geociencias (IGEO), CSIC-UCM, Madrid, Spain

12 (7) Dpto. CC de la Tierra y Astrofísica, Fac. de Ciencias Físicas, Universidad Complutense, Madrid, Spain

13 (8) Oeschger Centre for Climate Change Research and Institute of Geography, University of Bern, $\mathrm{CH}-$ 143012 Bern, Switzerland

$\left(^{*}\right)$ Corresponding author: juan.ballesteros@unige.ch

17 Abstract

We analyse the linkage between atmosphere-ocean mode and winter flood variability over the $20^{\text {th }}$ century based on long-term flow-discharge series, historical archives and tree-ring records of past floods in the North Atlantic Basin (NAB).The most extreme winter floods occurred in 1936 and had strong impacts on either side of the Atlantic. We hypothesize that the joint effects of Sea Surface Temperatures (SSTs) over the Atlantic and Pacific Oceans and the Arctic Oscillation (AO), which is closely related to the North Atlantic Oscillation- (NAO), play a significant role when describing flood variability in North America and Europe since 1900. Statistical modelling supports the assumption that the response of flood anomalies over the NAB to AO phases is subsidiary of SST phases. Besides, 
we shed light on the extraordinarily winter flood of 1936 that was characterized by very high SSTs over both the Atlantic and Pacific ( $>98^{\text {th }}$ percentile) and very low, negative values of $A O\left(<1^{\text {st }}\right.$ percentile). This outstanding winter flood episode was most likely characterized by stratospheric polar vortex anomalies, which can usually be linked to an increased probability of storms in W and SW Europe and increased snowfall events in E North America. By assessing the flood anomalies over the NAB as a coupled $A O$ and SST function, one could indeed further the understanding of such large-scale events and presumably improve anticipation of future extreme flood occurrences.

\section{Introduction}

The recent intense winter floods in northern and central Europe have revealed the need for an improved understanding of the triggering mechanisms of these events, not least to ameliorate existing climate impact models and mid-term weather forecasts ${ }^{1-3}$. For instance, the debate related to the intense $2013 / 14$ winter floods in the UK ${ }^{4-6}$ has revealed a noteworthy disagreement on the attribution of extreme events at small spatial scales. Some studies have argued that extreme events such as the $2013 / 14$ floods are highly sitespecific, as supported by the lack of correlation between large-scale teleconnections and precipitation records over the UK, thus preventing attribution to large-scale drivers ${ }^{5}$. However, large scale climate modes of variability have been widely related to precipitation and temperature anomalies in the Northern Hemisphere.

The main hemispheric-wide pattern of variability in the North Hemisphere is known as the Arctic Oscillation (AO) or the annular mode ${ }^{7}$. The AO represents the wind circulating counter-clockwise around the Arctic, thereby strongly driving the location and intensity of the mid-altitude jet stream, and consequently patterns of zonal and meridional heat and moisture transport. The North Atlantic Oscillation (NAO) is considered as a regional manifestation of the $A O^{7}$ and is defined by the difference in sea-level pressure between Greenland and a mid-latitude sector of the North Atlantic Ocean (Azores). Changes in the North Hemisphere pattern of variability have been described as a modulating factor for rainfall distribution patterns and extreme events in Europe ${ }^{8-11}$. Thus, between $30^{\circ}$ and $45^{\circ} \mathrm{N}$ on either side of the Atlantic, the largest floods have been correlated with NAO phases ${ }^{12-15}$. The Atlantic Multidecadal Oscillation (AMO-like) SST anomalies have been also linked to decadal climate fluctuations in precipitation over India, the Sahel, 
Europe $^{16-18}$. The Pacific Decadal Oscillation (PDO) also plays a role in the climate system, affecting North America ${ }^{19}$ and Europe ${ }^{20}$. These phenomena typically experience fluctuations at multi-decadal time scales, however their combination has also been described as a predictor of weather regimes ${ }^{21-24}$. Nevertheless, the main drawback tor analyse the role of these climate modes of variability on extreme hydrological events lies in the lack of instrumental records ${ }^{4,5}$. Existing flow gauge records are therefore often restricted to the recent decades, with a few exceptions ${ }^{25,26}$. This shortage of systematic records can sometimes be overcome with historical and paleoflood data ${ }^{27}$. The combination between systematic, historical, and paleofloods records, derived from different geological ${ }^{27}$ and natural archives ${ }^{28}$, has improved our understanding about the frequency, magnitude, and triggering mechanisms of extreme flood events ${ }^{27,29}$ considerably, and also often constitutes the unique, real evidence of impacts of rare extreme events which normally are absent in the flow records. Thus, even if we cannot necessarily assume that extreme past flood patterns will be repeated in the future ${ }^{30}$, we realize that long-term records can indeed contain the critical information needed to better understand flood-climate linkages at regional and global scales ${ }^{14}$.

Here, we aim at identifying linkages between winter flood events in the North Atlantic Basin (NAB) over the last century and the main atmosphere-ocean modes present during these events. To this end, we collected and analysed existing flow discharge series from all major rivers draining the NAB. Unlike most of the previous work on the topic, historical records on floods and tree-ring based palaeoflood reconstructions covering the $20^{\text {th }}$ century have been included to complement the geographical distribution of each episode of past extreme floods. Screening of this dataset has then enabled identification of winter flood anomalies over the NAB during the full $20^{\text {th }}$ century, including a characterization of an extraordinary winter flood episode in early 1936. Results of this study highlight quite clearly the impact of atmosphere-ocean coupled modes on extreme floods, and could therefore help to place the recent flood events in Europe (e.g., the 2014 floods in the UK) in a much wider temporal and spatial context.

\section{Material and methods}

\subsection{Flow measurements, historical and paleoflood records}

We selected all long-term flow-gauge station data from Portugal, Spain, France, the United Kingdom, and the eastern U.S (Table S1). They were retrieved from the U.S. Water Resources Administration archive (www.water.usgs.gov/floods/), UK National River Flow Archive (www.nrfa.ceh.ac.uk/); HYDRO database of the Ministère de l'Ecologie (www.hydro.eaufrance.fr) in France, MAGRAMA dataset of the Ministerio de 
Agricultura, Energía y Medio Ambiente (www.magrama.gob.es/) in Spain, and the Sistema Nacional de Informacão (wwwsnirh.pt/) in Portugal. Only flow data reaching back to at least 1930 were selected for analysis. For each station, we extracted maximum winter (i.e. December-March) peak discharge (in $\mathrm{m}^{3} \mathrm{~s}^{-1}$ ) and computed the flood standardised anomalies $\left(F_{a}\right)$ with respect to the reference period 1981-2016 using data from a total of 107 flow gauge stations (65 in the U.S. and 42 in Europe) as follows (Eq. 1):

$$
F_{\mathrm{Q}}=\frac{x_{\mathrm{l}}-\overline{\bar{x}_{\mathrm{ref}}}}{\sigma_{\mathrm{ref}}}
$$

, where Xi represents the maximum flood recorded in DJFM in each year of the record, $\overline{X_{r \ell I^{\prime}}}$ and where $\sigma_{r a f}$ are the average and standard deviation values, respectively, for the reference period.

To complement the information in regions with an obvious lack of data, we added flood records from documentary sources, mostly newspapers and technical reports, as well as paleoflood data obtained through tree-ring reconstructions ${ }^{13}$. Spain was the region where most proxy records were used; this is because the beginning of the Civil War (1936-1939) resulted in a complete loss of records. Overall, we collected six technical reports, consulted twenty-three historical archives, used five tree-ring based flood reconstructions, one video, and several contemporary pictures of the 1936 flood events on either side of the Atlantic (Table S2; Figure S1).

\subsection{Climate data}

We used indices of oceanic variability modes in the Northern Hemisphere, two families of reanalyses datasets $\left(20 \mathrm{CRV} 2 \mathrm{c}^{31}, \mathrm{ERA}-20 \mathrm{c}^{32}\right)$, an ensemble of 10 atmospheric model simulations (ERA-20CM ${ }^{33}$ ) and statistical reconstructions ${ }^{34,35}$. Information on the AO, PDO and AMO indices was retrieved from the NOAA website (http://www.esrl.noaa.gov/). The AO is defined here as the leading mode of Empirical Orthogonal Function (EOF) of monthly mean $1000 \mathrm{mb}$ heights. AMO index is based on the area-weighted averaged SST from the Kaplan SST V2 dataset over the North Atlantic $\left(0-70^{\circ} \mathrm{N}\right)$, while the PDO is based on SST anomalies poleward of $20^{\circ} \mathrm{N}$ in the Pacific basin. The NAO index is defined as the difference in pressure between Iceland and Gibraltar. NAO data was been retrieved from the dedicated website of the Climate Research Unit, University of East Anglia (http://www.cru.uea.ac.uk). In terms of gridded reanalyses datasets, we used the NOAA $20^{\text {th }}$-century reanalysis Version 2 (20CRv2) and Version 2c (20CRv2c) from 

https://www.esrl.noaa.gov/psd/data/gridded/data.20thC ReanV2c.html. In addition, we also employed the ERA-20C reanalysis from the European Center for Mid-Term Weather Forecast

120 (http://apps.ecmwf.int/datasets/data/era20c-mnth/levtype=sfc/type=an/). Climatological anomalies were referenced to the period 1981-2010. In addition, we also used the statistical reconstructions of the global monthly mean geopotential field for the period 1880-2001: REC1 ${ }^{35}$, based on a principal component regression of surface and upper-air data; and REC2 ${ }^{34}$, based on grid-column by grid-column reconstruction using principal component regression. Both reconstructions are calibrated against ERA-40. Besides, we validated the reanalysed dataset with some of the first radiosonde measurements ever taken in IImala (Finland) during the winter of $1936^{36}$. The detection of atmospheric rivers was based on the Atmospheric River Archives from http://www.meteo.unican.es/atmospheric-rivers.

\subsection{Statistical flood-climate linkages}

We used the ppcaMethod R package to fit a Principal Component Analysis (PCA) based on data with missing values. To this end, we applied a probabilistic approach to perform a PCA with missing values ${ }^{37}$. The probabilistic Principal Component Analysis (PPCA) combines an expectation maximization (EM) approach with a probabilistic model (for details see Stacklies et al., ${ }^{37}$ ). Then, we used Generalized Lineal Mixed-Effect models to investigate linkages between winter flood anomalies $(F a)$ over the NAB and interactive atmosphere-ocean effects. In the model, gauge stations were included as a random term to take into account the potential effect of specific uncertainties associated to each record and derived as a variance term in the model. According to our general hypothesis "winter flood anomalies in the NAB are related to the combination of atmosphere-ocean modes", we build the null hypothesis Ho: Fa = (intercept)+(random) and three alternative hypotheses: be explained by the interaction (juxtaposition) of the $A M O$ and $A O$ indices, but with a potential influence of the PDO; 

explained by the sum of the individual effects of the atmosphere-ocean mode.

The interaction introduced in $\mathrm{H} 1$ and $\mathrm{H} 2$ allows exploration of the possibility that one covariate could modify the influence of another covariate on the response variable. Alternatively, model $\mathrm{H} 3$ contains only the main effects of each covariate and thus assumes that each influence is independent from the others ${ }^{4,5}$. Model selection was based on the Akaike Information Criterion corrected for small sample sizes (AICc) ${ }^{38}$ and the Bayesian Information Criterion (BIC) ${ }^{39}$. The BIC was also used because it tends to penalize more severely model selection procedure than AIC. Alternative hypotheses were tested by using the delta AICc / BIC between each alternative hypothesis and the null hypothesis (i.e. AICc / BIC of the null model minus AICc / BIC of each model). All predictor variables were standardized prior to model fitting. The model assumption and collinearity were evaluated using the Variance Inflation Factor and the kappa indices (e.g. VIF, K).

\section{Results and Discussion}

\subsection{The interaction between $N A O$ and $A M O$ explain flood anomalies in the NAB}

The flood anomalies over the NAB are displayed in Fig. 1. The first PC (PC1) of the last century flood anomalies explains up to $41 \%$ of the variance (Fig. S2). NAB flood anomalies variability is in agreement with the periods of high or low flood activity as previously reported in western-central Europe ${ }^{14,15,26}$ and eastern North America ${ }^{9,25}$. Then, we tested whether the interaction between the winter (DJFM) AO and the AMO has any effect on the probability of flood occurrences over the NAB. To this end, we exclusively considered the $\mathrm{AO}$ index because the high correlation between the NAO and the $\mathrm{AO}(>0.8)$ would have induced collinearities in model performance (Fig. S3). The AICc criterion supports the assumption that the co-occurrence of anomalous AMO/AO phases plays a key role in interannual winter flood variability, with concurrent positive AMO phases and negative AO phases favouring winter floods over the NAB. We additionally found a modulating influence of the PDO on winter floods. This is supported by the difference between the AIC values of the Null Hypothesis $\mathrm{H}_{0}\left(\mathrm{AIC}-\mathrm{H}_{0}=27639.25\right.$, $\left.\mathrm{df}=3\right)$ and the alternative Hypothesis $\mathrm{H}_{1}$ (i.e. model including the effect of PDO; $\Delta \mathrm{AIC}-\mathrm{H}_{1}=-183.52$ and $\Delta \mathrm{BIC}-\mathrm{H}_{1}=-154.41 ; \mathrm{df}=7$ ) (see Methods and Table S3, Table S4 and Fig. S4). The same model selection is also supported by the use of the Bayesian information criterion (BIC; see Table S3 for details). Therefore, the coupled occurrence of positive $A M O$ phases and negative $A O / N A O$ phases leads to enhanced flood probability over the NAB and this signal can be further strengthened by the PDO, increasing the explained variance of NAB flood 
anomalies by up to $36 \%$ during its positive phase (Fig. 2). This behaviour has been observed for the period 1930-1950, and, more recently, again since the 1990s, which coincided with high winter floods over the NAB. On the contrary, weaker floods dominated during the 1960s-1980s, which matches with a positive trend in NAO and a decrease in NAB SSTs.

\section{Figure 1}

\section{Figure 2}

\subsection{The extreme winter floods episode of 1936}

The analysis of the flood records shows that the winter of 1935/36 saw the most extreme floods since at least the beginning of the $20^{\text {th }}$ century over the NAB (Fig. 1). The quantified average flood anomalies recorded over the NAB in winter 1935/36 reached values of 2.9, an anomaly exceeding six sigma values. This winter flood episode resulted in severe and widespread impacts on either side of the Atlantic (Fig. 3). The CRU and UDEL datasets confirm consistent (and locally large) positive precipitation anomalies during the $1935 / 36$ winter over the entire U.S. East Coast, from Florida to Maine, and in Western Europe, over Iberia and France (Fig. S5). Historical archives and tree-ring based reconstructions of floods in ungauged mountain catchments on both sides of the Atlantic further underline these exceptional floods (Table S2).

\section{Figure 3}

In eastern North America, severe floods occurred in Pittsburgh, New England, Upper Ohio, Georgia, Alabama, Mississippi, as well as in La Malbaie, Baie-Saint-Paul, and Saint-Jean. By way of example, in March 1936, the Connecticut River in Hartford reached a flood peak of about $8,850 \mathrm{~m}^{3} \mathrm{~s}^{-1}$. This value is, by far, the highest runoff peak measured at this location since the beginning of regular measurements in 1800 CE (Table S1). Likewise, the floods in March 1936 were, by far, the largest recorded to date in several other rivers in New England ${ }^{40}$. This is in agreement with tree-ring based flood records of the Potomac River (see Table S2), confirming the extreme character of the 1936 winter floods over the last two centuries.

In western Europe, intense floods occurred in the Duero, Tagus, Guadiana, Guadalquivir, and Ebro rivers on the Iberian Peninsula, as well as in the Rhone, Loire, and Garonne Rivers of France. Paleoflood records 
retrieved from four ungauged mountain catchments in central Spain reveal extreme torrential activity at the regional scale and point to this event as the most outstanding disaster, at least in terms of geomorphic imprint, since the late $18^{\text {th }}$ century. In the case of the Tagus River (Vila Velha, Portugal), six consecutive flood peaks were recorded between December 24, 1935 and April 15, 1936, leading to over 20 villages of the lower Tagus being submerged by water for over 127 days, representing the most significant flooding episode on record in terms of its duration. The highest flood of the season was recorded on January 22 , 1936 with a peak flow of $8,800 \mathrm{~m}^{3} \mathrm{~s}^{-1}$ for a catchment area of $59,167 \mathrm{~km}^{2}{ }^{41}$. A quite exceptional flood duration was also reported for the Garonne river (southern France), where a succession of four floods between December 3, 1935 and February 4, 1936 produced the largest accumulated flow volume (18.1 $\mathrm{km}^{3}$ ) measured to date ${ }^{42}$. In March 1936, large floods were also experienced at higher latitudes, such as at the Nith River (northern UK), but also at more meridional latitudes in northern Morocco (Table S2).

\subsection{A potential explanation on the triggers of the 1936 floods}

During the winter of 1935/36, the global atmosphere-ocean pattern was particularly remarkable. SSTs over the Pacific did not reveal substantial anomalies, suggesting neutral El Niño-Southern Oscillation (ENSO) conditions. However, both the AMO $(+0.39)$ and PDO $(+1.63)$ were strongly positive, exceeding the $98^{\text {th }}$ and the $95^{\text {th }}$ percentiles, respectively. The $\mathrm{NAO}_{\text {DJFM }}$ index $(-3.89)$ and its closely-related $\mathrm{AO}_{\text {DJFM }}$ index (2.64) displayed extremely low values, roughly at the $\sim 1^{\text {st }}$ percentile. Interestingly, the juxtaposition of these extreme positive values in AMO and PDO, and negative values in NAO has no analogues since 1900, and therefore represents a unique condition for the winter 1935/36 (Fig. S6). These results are in agreement with the statistical model (previous section), further supporting the hypothesis that flood anomalies over the NAB are indeed linked to the physical interaction between oceanic and atmospheric phenomena. These findings emphasize the need to consider the superimposed effects of several climatic modes, rather than focusing on their individual effects for flood attribution ${ }^{5}$. Noteworthy, the 1935/36 winter flood occurred during a period (1910s-1940s) of strong internal variability of the climate system, also known as the Early Twentieth Century Warming, which featured an anomalous warming of the Arctic region impacting climate both in North America (with the so-called Dust Bowl droughts) and northern Europe ${ }^{43}$.

Remarkably, in addition to the troposphere-ocean modes, the stratosphere could also have favoured the occurrence of the largest floods of the $20^{\text {th }}$ century on either side of the NAB. Although we are aware of uncertainties related to the characterization of stratosphere dynamics during the early $20^{\text {th }}$ century due to 
the lack of observations, several lines of evidence point to a potential role of stratospheric anomalies during this event, which could indeed have helped to enhance the tropospheric response. In that regard, the reconstructed Quasi-Biennial Oscillation (QBO) suggests an easterly phase of the equatorial zonal winds, which would have changed to the westerly phase at the end of the winter ${ }^{44}$. The easterly phase of the QBO has been related to a weaker Northern Hemisphere stratospheric polar vortex, through the so-called Holton-Tan mechanism ${ }^{45-47}$. Conversely, sea-surface temperature also favoured a weak stratospheric polar vortex, as evidenced by the composite anomaly of the wind field at $65^{\circ} \mathrm{N}$ and $200 \mathrm{hPa}$ based on ERA20CM. Results suggest weaker zonal winds in the upper troposphere-lower stratosphere (Fig S7). The reanalyses data and the statistical reconstructions (Fig.4; Fig. 5; Fig. S8, Fig. S9) suggest a polar vortex deformation starting in February and lasting until March 1936. The associated weakening of the polar night jet stream is characteristic of negative phases of the Northern Annular Mode (NAM), which, in the stratosphere / troposphere, is associated with the strength of the polar vortex / the extratropical jet stream. It is therefore possible that these phenomena could have influenced the formation and unusual nature of the winter floods in $1935 / 36$.

However, we are well aware that surface-only reanalyses may not be accurate in the stratosphere. For this reason, we compared them with independent, direct measurements, i.e., data from six radiosonde ascents from Ilmala / Helsinki which reached the $200 \mathrm{hPa}$ level during the winter of 1935/36 ${ }^{48}$ (Table S5). The correlations with $20 \mathrm{CRv} 2 \mathrm{c}$ for temperature and geopotential height are 0.74 and 0.98 , respectively. A good agreement is further supported by the correlation between total column ozone in $20 \mathrm{CRv} 2$ and historical observations, after subtracting an annual mean cycle ${ }^{49}$. Pearson correlation coefficients for the period October 1935 to April 1936 are 0.42 for Arosa (Swiss Alps; $n=100), 0.41$ for Oxford (UK; n=13) and 0.38 for Zi-Ka-Wei, Shanghai (China; n=59).

Previous studies have shown that polar stratospheric anomalies during winter can propagate downwards into the troposphere in the form of negative NAM phases, causing long-lasting impacts at the surface ${ }^{50}$. The so-called stratosphere-troposphere coupling appears to be present across all timescales, from weekly

271 to decadal ${ }^{51,52}$. We therefore argue that the stratospheric vortex anomalies detected from January to March 2721936 could indeed have contributed to the amplification of the negative AO/NAO phase ${ }^{47,53,54}$. This is also supported by the latitude-pressure cross-section of the zonal mean anomalies during February and March 1936, which indicates weaker zonal winds (i.e., negative NAM phases) propagating from high to low levels through the winter season (Fig S10). This negative AO-like tropospheric configuration is also characteristic 
of a persistent blocking activity over the NAB and Greenland ${ }^{55,56}$, which in turn has been related to positive AMO phases through the $20^{\text {th }}$ century ${ }^{57}$. Blocking tends to promote the advection of moist air masses from the warmer Caribbean Sea, contributing to widespread precipitation on low-to-mid latitudes of either side of the Atlantic ${ }^{57}$. The positive PDO could have further contributed to warmer Northeast coast SST anomalies by enhancing the advection of cold Artic air masses across the eastern U.S. In fact, the major flood episode of 1936 matches with the occurrence of atmospheric rivers across the NAB originated over the warmer Caribbean ${ }^{58,59}$ (Table S6, Fig. S11, Fig. S12), which often results in long-lasting precipitation and snowmelt processes.

\section{Conclusions}

The analysis of the flood variability and extremes over the last century is relevant to understand changes in the Anthropocene ${ }^{60}$. Here, we focus on winter floods in the North Atlantic Basin (NAB), a region that is frequently exposed to flooding. According to our results, flood variability over the NAB can be explained as a juxtaposition of the main atmosphere-ocean modes of variability. Thus, the flood activity over the NAB could be enhanced by the coupled occurrence of positive AMO phases and negative AO/NAO phases. The findings of this study thus also imply that the attribution of flood variability over the course of the $20^{\text {th }}$ century should not be exclusively based on individual climate modes. Our results also highlight how outstanding winter conditions were in 1935/36, both in terms of atmosphere-ocean conditions, but also with respect to extreme flood activity over the NAB. The record-breaking flood event of winter $1935 / 36$ is indeed in agreement with the simultaneous occurrence of very positive AMO and PDO phases and very negative $\mathrm{AO} / \mathrm{NAO}$ phases, to a degree that has not been observed at any other moment of the $20^{\text {th }}$ and early $21^{\text {st }}$ centuries. Based on analyses, we suggest that the occurrence of stratospheric anomalies in winter 1935/36 would indeed have increased the tropospheric weather response, as in the case of the UK winter floods of $2013 / 14^{4}$. Such a polar vortex split in the $\mathrm{N}$-polar stratosphere can effectively be linked to an increased probability of storms in W and SW-Europe and increased snowfall events in Eastern North America, which in turn may lead to extreme flood events ${ }^{48}$. Our findings have major implications on our understanding of the co-occurrence of flood over the NAB. Moreover, the fact that the winter 1936 took place during the Early Twentieth Century Warming period makes this winter a valuable candidate to understand potential analogues in a warming $21^{\text {st }}$-century world, and consequently improve the anticipation of impacts in the future. 
308 Acknowledgements

309 This study was funded by the Institute for Environmental Sciences (University of Geneva) without any 310 specific grant. We are grateful to the PAGES Flood Working Group for promoting exchange of ideas as well 311 as to the climate modelling community for their valuable contributing and for making available their model 312 output. Support for the Twentieth Century Reanalysis Project version $2 \mathrm{c}$ dataset is provided by the U.S. 313 Department of Energy, Office of Science Biological and Environmental Research, and by the National 314 Oceanic and Atmospheric Administration Climate Program Office. ERA-20C and ERA-20CM were provided 315 by the ECMWF. SB acknowledges support from the FP7 project ERA-CLIM2. JABC thanks Sebastian 316 Guillet, Christophe Corona and Jaime Madrigal for their comments. GB appreciates the support of 317 Fundación Biodiversidad (MAPAMA) through research project DAM-ADAPT. D.B. and R.G.-H. were 318 supported by the Spanish Ministry of Economy and Competitiveness through the PALEOSTRAT 319 (CGL2015-69699-R) project and the European Project 603557-STRATOCLIM under program FP7$320 \quad$ ENV.2013.6.1-2.

321 Additional Information

322 Authors declare no competing financial interests. 


\section{References}

1. Hirabayashi Y., R. Mahendran, S. Koirala, et al. 2013. Global flood risk under climate change. Nat. Clim. Chang. 3: 816-821.

2. Arnell N.W., S.N. Gosling. 2014. The impacts of climate change on river flood risk at the global scale. Clim. Chang. 134(3): 387-401. .

3. Dankers R., N.W. Arnell, D.B. Clark, et al. 2013. First look at changes in flood hazard in the Inter-Sectoral Impact Model Intercomparison Project ensemble. Proc. Nat. Acad. Sci. 111(9): 32573261.

4. Huntingford C., T. Marsh, A.A. Scaife, et al. 2014. Potential influences on the United Kingdom's floods of winter 2013/14. Nat. Clim. Chang. 4: 769-777.

5. Oldenborgh G.J., Van D.B., Stephenson A., Sterl, et al. 2015. Drivers of the 2013 / 14 winter floods in the UK. Nat. Clim. Chang. 5: 490-491.

6. Schaller N., A.L. Kay, R. Lamb, et al. 2016. Human influence on climate in the 2014 southern England winter floods and their impacts. Nat Clim Chang 6(6): 627-634.

7. Thompson D.W.J., J.M. Wallace. 1998. The Arctic Oscillation signature in wintertime geopotential height and temperature fields. Geophys. Res. Lett. 25: 1297 - 1300.

8. Sutton R.T., D.L.R. Hodson. 2013. Atlantic Ocean Forcing of North American and European Summer Climate. Science 309: 115-118.

9. Hayhoe K., M. Schwartz. 2016. Past and future changes in climate and hydrological indicators in the US Northeast. Clim. Dyn. 28(4): 381-407.

10. Delworth T.L., M.E. Mann. 2000. Observed and simulated multidecadal variability in the Northern Hemisphere. Clim. Dyn. 16(9): 661-676.

11. Beniston, M. 2018. Modulation of extreme temperatures in Europe under extreme values of the North Atlantic Oscillation Index. Ann. N. Y. Acad. Sci. (in press)

12. Salgueiro A.R., M.J. Machado, M. Barriendos, et al. 2013. Flood magnitudes in the Tagus River (Iberian Peninsula) and its stochastic relationship with daily North Atlantic Oscillation since mid-19th Century. J. Hydrol. 502: 191-201.

13. Ballesteros-Cánovas J.A., C. Rodríguez-Morata, V. Garófano-Gómez, et al. 2015. Unravelling past flash flood activity in a forested mountain catchment of the Spanish Central System. J. Hydrol. 529: 468479.

14. Benito G., M.G. Macklin, A. Panin, et al. 2000. Recurring flood distribution patterns related to shortterm Holocene climatic variability. Nat. Sci. Rep. 5: 16398 
15. Wirth S.B., A. Gilli, A. Simonneau, et al. 2013. A 2000-year long seasonal record of floods in the southern European Alps European Alps. Res. Lett. 40(15): 4025-4029. .

16. McCarthy G.D., I.D. Haigh, J.J.-M. Hirschi, et al. 2015. Ocean impact on decadal Atlantic climate variability revealed by sea-level observations. Nature 521: 508-510.

17. Reilly C.H.O., M. Huber, T. Woollings, et al. 2016. The signature of low-frequency oceanic forcing in the Atlantic Multidecadal Oscillation. Geophys. Res. Lett. 43(6): 2810-2818.

18. Peña-Ortiz C., D. Barriopedro \& R. García-Herrera. 2015. Multidecadal variability of the summer length in Europe. J. Clim. 28: 5375-5388.

19. Mantua E.A. 1997. Pacific interdecadal climate oscillation with impacts on salmon production, $B$. Am. Meteorol. Soc 78: 1069-1079.

20. Brönnimann S., E. Xoplaki, C. Casty, et al. 2007. ENSO influence on Europe during the last centuries. Clim. Dyn. 28: 181-197.

21. Chen S., Wu R, Chen W. 2015. The changing relationship between interannual variations of the North Atlantic Oscillation and Northern Tropical Atlantic SST. J. Clim 28(2): 485-504.

22. Madrigal-González, J., Ballesteros-Cánovas, J. A., Herrero, A., Ruiz-Benito, P., et al., 2017. Forest productivity in southwestern Europe is controlled by coupled North Atlantic and Atlantic Multidecadal Oscillations. Nat. Comm., 8(1): 2222

23. Gastineau G, Frankignoul, C. 2015. Influence of the North Atlantic SST variability on the atmospheric circulation during the twentieth century. J. Clim 28(4): 1396-141624.

24. Czaja A., A.W. Robertson \& T. Huck. 1998. The Role of Atlantic Ocean-Atmosphere Coupling in Affecting North Atlantic Oscillation Variability. The North Atlantic Oscillation: climatic significance and environmental impact, 147-172.

25. Archfield S.A., R.M. Hirsch, A. Viglione, et al. 2016. Fragmented patterns of flood change across the United States. Geophys. Res. Lett. 43(19): 10.232-10.239..

26. Mediero L., T.R. Kjeldsen, N. Macdonald, et al. 2015. Identification of coherent flood regions across Europe by using the longest streamflow records. J. Hydrol. 528: 341-360.

27. Baker V.R. 2008. Paleoflood hydrology: Origin, progress, prospects. Geomorphology 101: 1-13.

28. Ballesteros-Cánovas J.A., M. Stoffel, S. St George, et al. 2015. A review of flood records from tree rings. Prog. Phys. Geogr. 39(6): 794-816.

29. Bodoque J.M., A. Díez-Herrero, M.A. Eguibar, et al. 2015. Challenges in paleoflood hydrology applied to risk analysis in mountainous watersheds - A review. J. Hydrol. 529: 449-467. 
30. Milly P.C.D., J. Betancourt, M. Falkenmark, et al. 2008. Climate change. Stationarity is dead: whither water management? Science 319: 573-574.

31. Compo G.P., J.S. Whitaker, P.D. Sardeshmukh, et al. 2011. The Twentieth Century Reanalysis Project. Q. J. R. Meteorol. Soc. 137: 1-28.

32. Poli P., H. Hersbach, D.P. Dee, et al. 2016. ERA-20C: An atmospheric reanalysis of the twentieth century. J. Clim. 29: 4083-4097.

33. Hersbach H., C. Peubey, A. Simmons, et al. 2015. ERA-20CM: A twentieth-century atmospheric model ensemble. Q. J. R. Meteorol. Soc. 141: 2350-2375.

34. Brönnimann, S., T. Griesser A.S. 2012. A gridded monthly upper-air data set from 1918 to 1957. Clim. Dyn. 38: 475-493.

35. Griesser T., S. Brönnimann, A. Grant, et al. 2010. Reconstruction of global monthly upper-level temperature and geopotential height fields back to 1880. J. Clim. 23: 5590-5609.

36. Stickler A., Grant A. N., Ewen T., Ross T. F., Vose R. S., Comeaux J.,et al., (2010). The comprehensive historical upper-air network. Bull. Am. Meteorol. Soc. 91(6): 741-752.

37. Stacklies W., H. Redestig, M. Scholz, et al. 2007. pcaMethods - A bioconductor package providing PCA methods for incomplete data. Bioinformatics 23: 1164-1167.

38. Burnham K.P., D.R. Anderson, K.P. Huyvaert. 2011. AIC model selection and multimodel inference in behavioral ecology: Some background, observations, and comparisons. Behav. Ecol. Sociobiol. 65: 23-3 39. Schwarz G. 1978. Estimating the dimension of a model. Ann. Stat. 461-464.

40. NC G. 1937. The floods of march 1936, part 1. New Engl. river.

41. Oliveira A N.A.-M. 1938. Anuario dos Serviços Hidráulicos 1936. Relatório das cheias do Tejo do ano de 1935-1936. In Imprensa Nacional.

42. Pardé M. 1936. Les crues de la Garonne en 1935 et au début de 1936. Rev. Geogr. Pyren. Sud. Ouest. 7: 206-211.

43. Brönnimann S. 2009. Early twentieth-century warming. Nat. Geosci. 2: 735-736.

44. Brönnimann S., J.L, Annis, C. Vogler, P.D. Jones, 2007. Reconstructing the quasi-biennial oscillation back to the early 1900s. Gephy. Res. Lett., 34(22).

45. Castanheira J.M., D. Barriopedro. 2010. Dynamical connection between tropospheric blockings and stratospheric polar vortex. Gephy. Res. Lett. 37: 1-5. 
46. Buchan J., J.J.-M. Hirschi, A.T. Blaker, et al. 2014. North Atlantic SST Anomalies and the Cold North European Weather Events of Winter 2009/10 and December 2010. Mon. Weather Rev. 142: 922932.

47. Baldwin M.P., T.J. Dunkerton, M.P. Baldwin, et al. 2016. Stratospheric harbingers of anomalous weather regimes. Science, 294(5542): 581-584.

48. Stickler A., S. Brönnimann, M.A. Valente, et al. 2014. ERA-CLIM: Historical surface and upper-air data for future reanalyses. Bull. Am. Meteorol. Soc. 95: 1419-1430.

49. Brönnimann S C.G.-P. 2012. Ozone highs and associated flow features in the first half of the twentieth century in different data sets. Meteo Zeit 21: 49-59.

50. Reichler T., J. Kim, E. Manzini, et al. 2012. A stratospheric connection to Atlantic climate variability. Nat. Geosci. 5: 783-787.

51. Langematz U. 2003. Thermal and dynamical changes of the stratosphere since 1979 and their link to ozone and CO 2 changes. J. Geophys. Res. 108: 4027.

52. Dyn C. \& E. Manzini. 2013. Stratosphere key for wintertime atmospheric response to warm Atlantic decadal conditions. Clim. Dyn. 42(3-4): 649-663

53. Kidston J., A.A. Scaife, S.C. Hardiman, et al. 2015. Stratospheric influence on tropospheric jet streams, storm tracks and surface weather. Nat. Geosci., 8(6): 433.

54. Ineson S., A.A, Scaife. 2009. The role of the stratosphere in the European climate response to El Niño. Nat. Geosci. 2: 32-36.

55. Kuroda Y. 2008. Role of the stratosphere on the predictability of medium-range weather forecast: A case study of winter 2003 - 2004. Gephys. Res. Lett: 35: 1-5.35: 1-5.

56. Marshall A.G., A.A. Scaife. 2010. Improved predictability of stratospheric sudden warming events in an atmospheric general circulation model with enhanced stratospheric resolution. J. Geophys. Res: Atm 115: $1-7$.

57. Häkkinen S., P.B. Rhines, D.L. Worthen. 2011. Atmospheric blocking and Atlantic multidecadal ocean variability. Science (80) 334: 655-659.

58. Gimeno L., R. Nieto, M. Vázquez, et al. 2014. Atmospheric rivers : a mini-review. Fron.Earth Sci., 2: 1-6.

59. Lavers D.A., R.P. Allan, G. Villarini, et al. Future changes in atmospheric rivers and their implications for winter flooding in Britain. Environ. Res. Lett. $\mathbf{3 4 0 1 0}$ 
60. Brönnimann, S., Ewen, T., Luterbacher, J., Diaz, H. F., Stolarski, R. S., \& Neu, U. (2008). A focus on climate during the past 100 years. In Climate variability and extremes during the past 100 years (pp. 125). Springer Netherlands. 
FIGURES

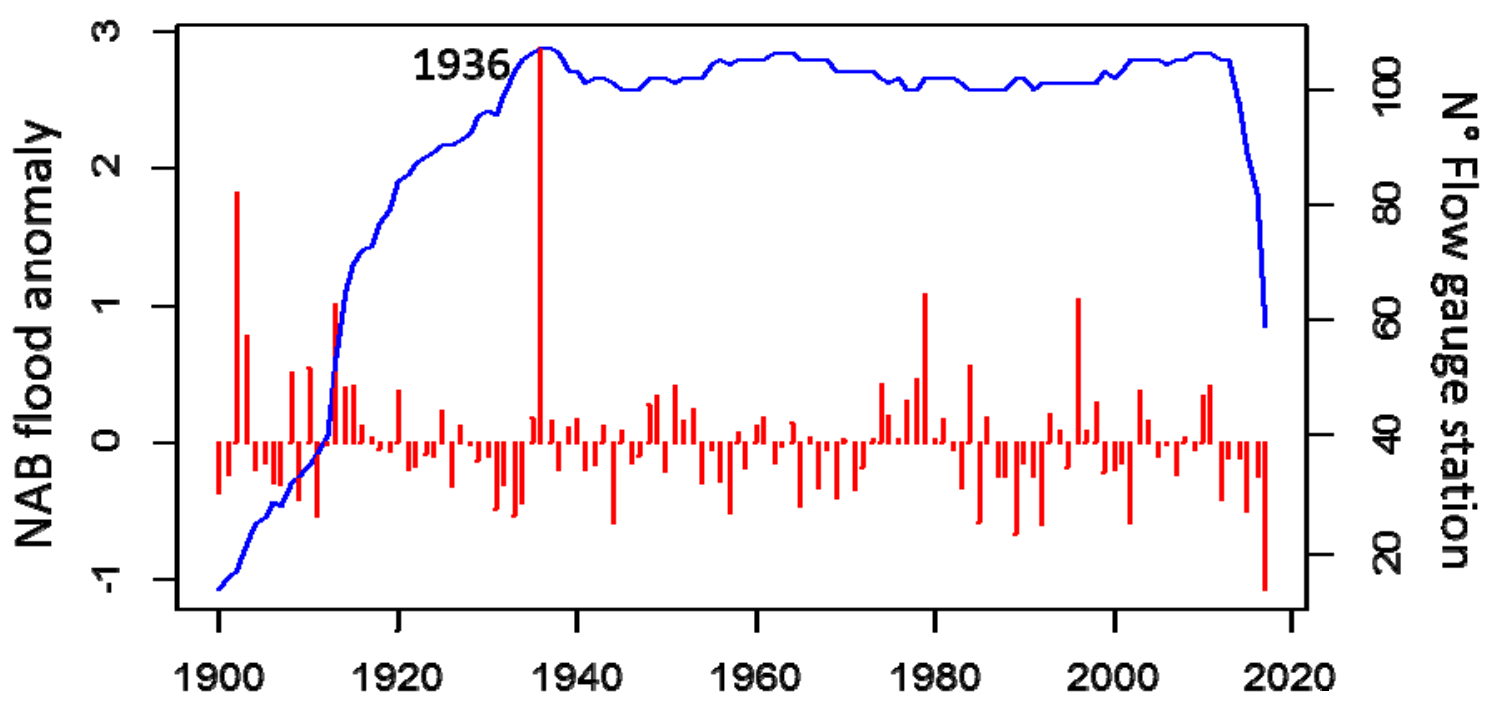

Figure 1: Mean winter flood anomaly over the North Atlantic Basin (NAB) based on 106 flow gauge stations. The flood anomaly of 1936 is by far the highest on record, with a value of +2.9 .

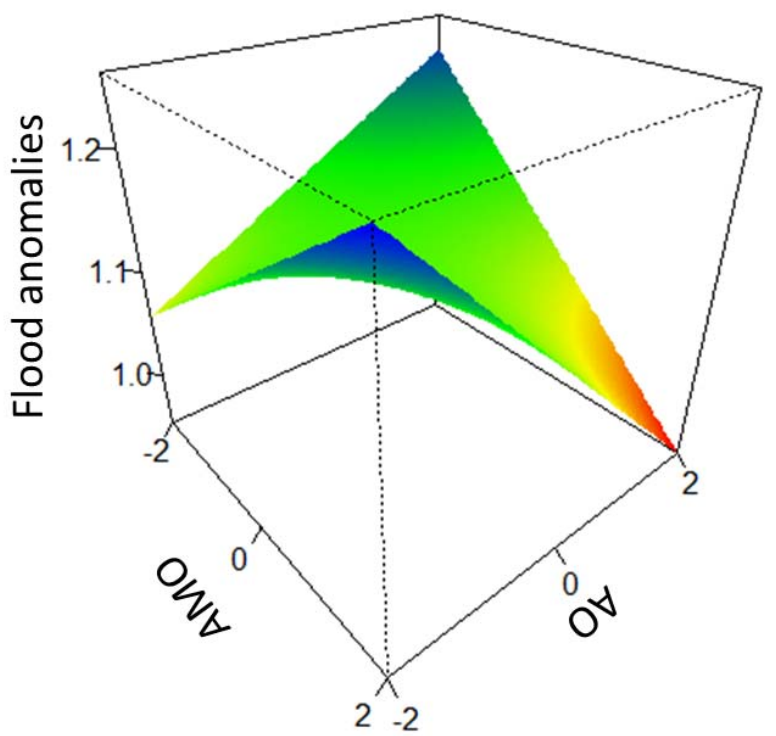

Figure 2: 3D regression plot showing predicted flood anomalies over the NAB according to the standardized AMO and AO indices. The colored layout (in which flood anomalies increase from red to blue) represents the marginal response curve when the other variables in the best model are varying. The number of cases is shown in Table S3. Graph created using R (www.r-project.org). 


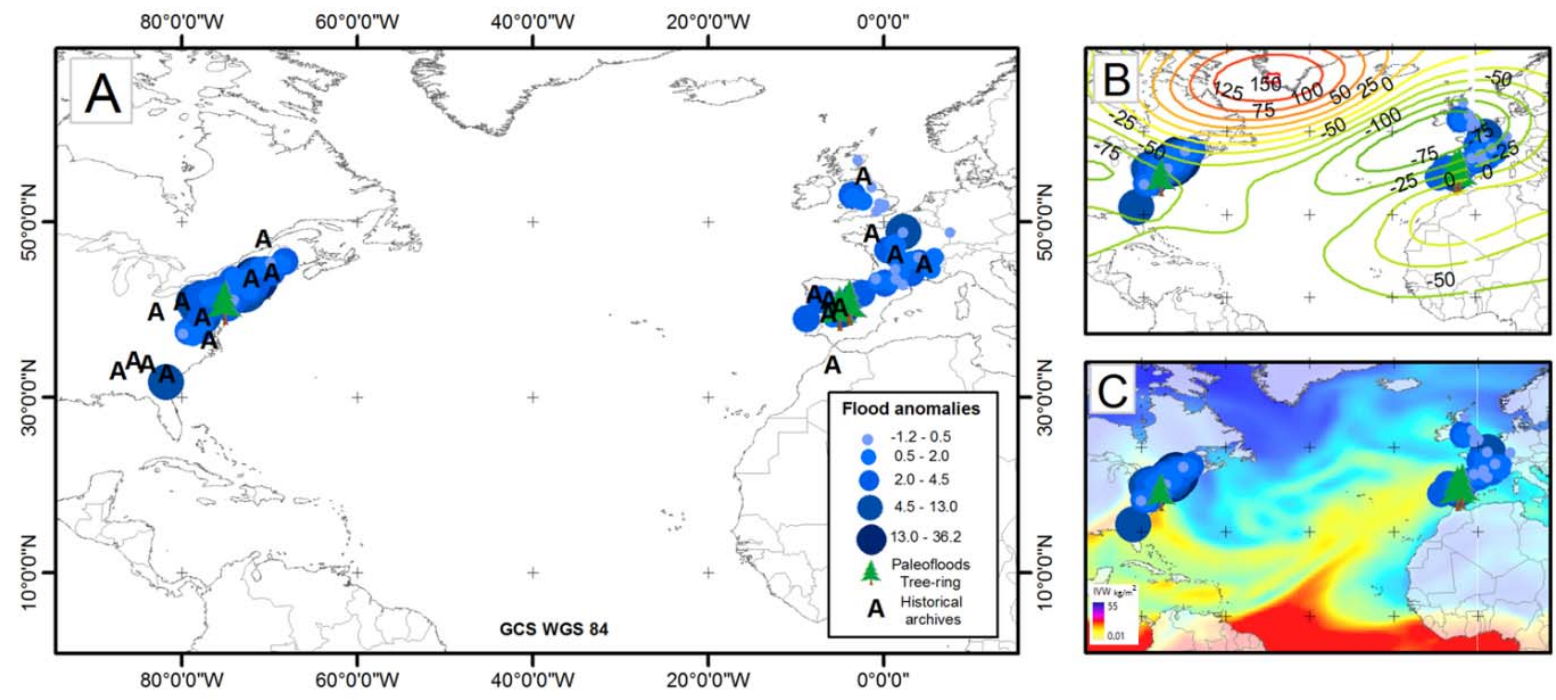

Figure 3: A) Spatial representation of the flood anomalies, historical records, and tree-ring flood reconstructions during the winter of 1935/36. B) Winter mean (December 1935 to March 1936) geopotential anomaly at $200 \mathrm{hPa}$ (in gpm). C) Integrated water vapor (kg m² $)$ on March 27, 1936 (data source: ERA-20c). Maps have been created using ArcGIS 10.1 (www.esri.com).
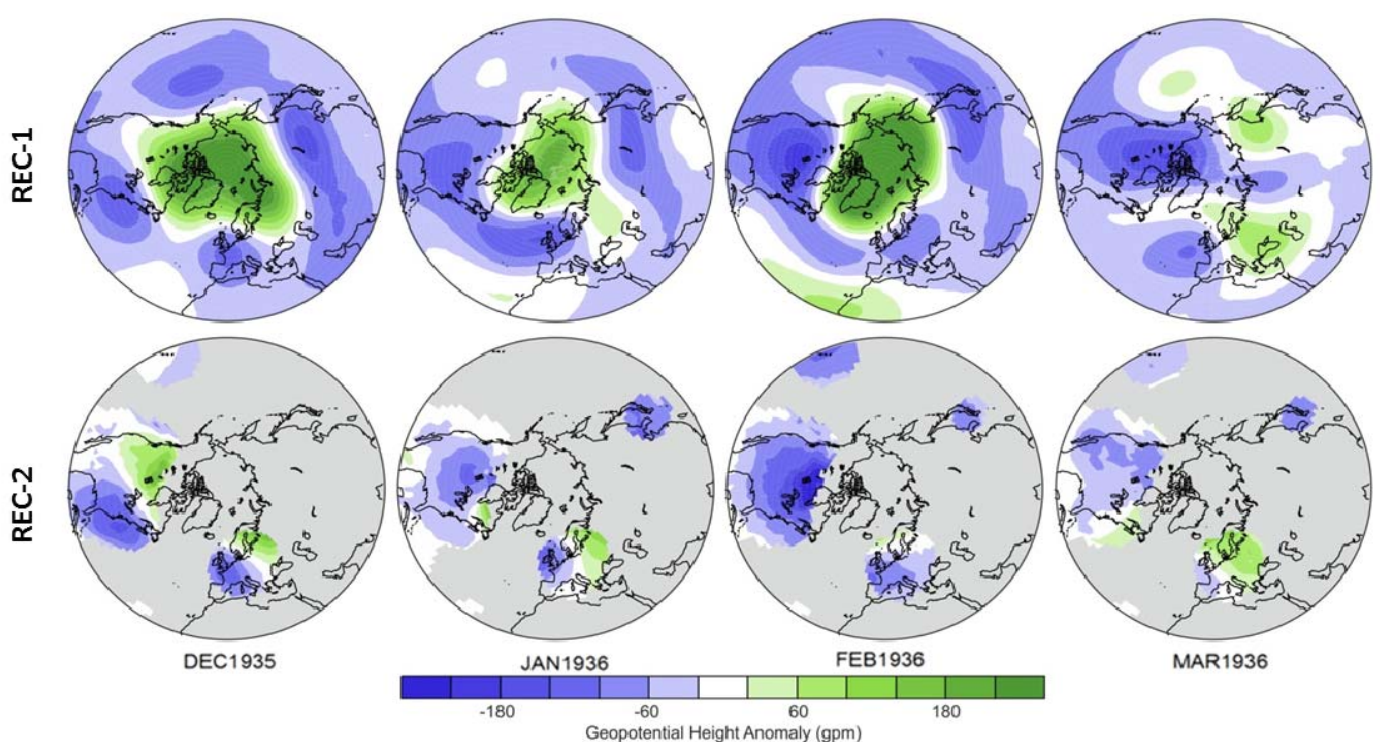

Figure 4. Monthly evolution of the geopotential height anomalies (gpm) at $100 \mathrm{hPa}$ from December 1935 to March 1936, based on the statistical reconstruction (see Methods). Maps have been created using MatLab (www. mathworks.com). 


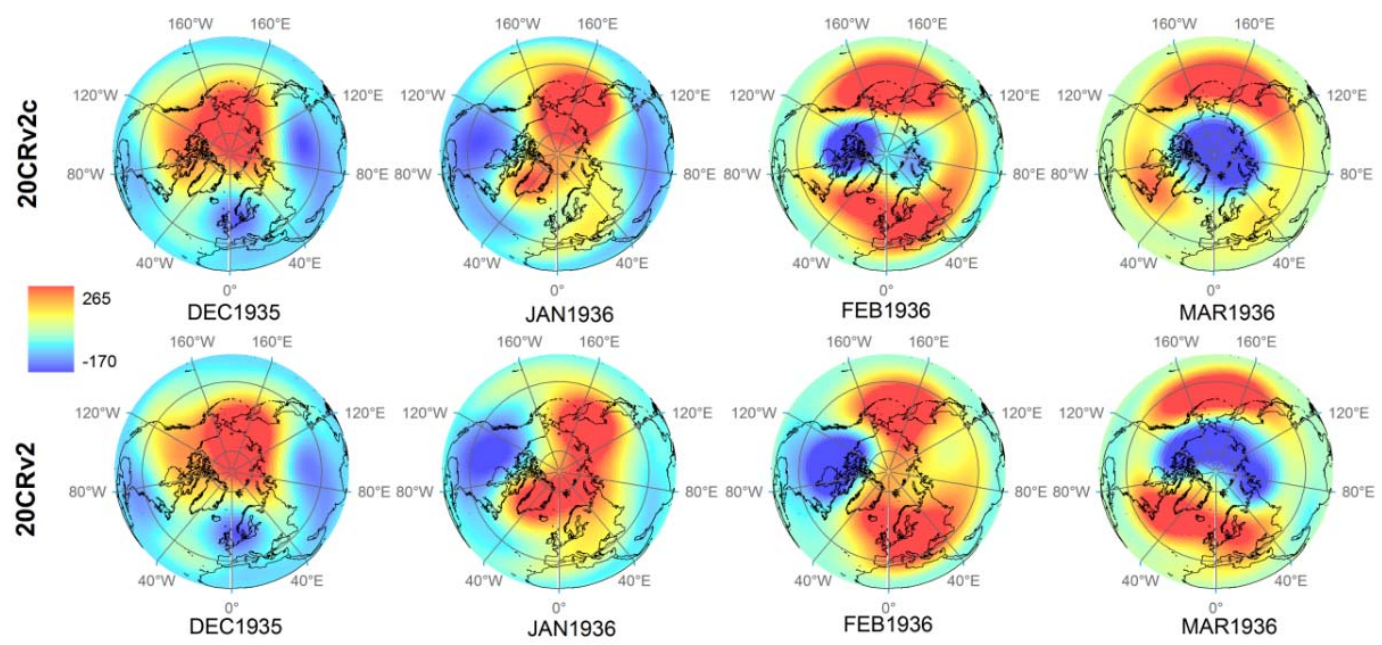

Figure 5. Evolution of the monthly mean geopotential anomaly (gpm) at the $70 \mathrm{hPa}$ level based on the $20 \mathrm{CRv} 2 \mathrm{c}$ reanalyses dataset. 